\title{
Balkanologie
}

Balkanologie Revue d'études pluridisciplinaires

Vol. IX, n' 1-2 | 2005

Volume IX Numéro 1-2

\section{Varro (Gabrielle), éd., Regards croisés sur l'ex- Yougoslavie. Des chercheurs face à leurs objets de recherche et aux événements sociaux et politiques,}

Paris : L'Harmattan (« Espaces interculturels»), 2005, 246 p.

François Ruegg

\section{OpenEdition}

Journals

Édition électronique

URL : http://journals.openedition.org/balkanologie/2015

DOI : 10.4000/balkanologie.2015

ISSN : 1965-0582

Éditeur

Association française d'études sur les Balkans (Afebalk)

Édition imprimée

Date de publication : 1 décembre 2005

ISSN : 1279-7952

\section{Référence électronique}

François Ruegg, « Varro (Gabrielle), éd., Regards croisés sur l'ex-Yougoslavie. Des chercheurs face à leurs objets de recherche et aux événements sociaux et politiques, ", Balkanologie [En ligne], Vol. IX, n 1-2 I

2005, mis en ligne le 14 janvier 2010, consulté le 17 décembre 2020. URL : http://

journals.openedition.org/balkanologie/2015; DOI : https://doi.org/10.4000/balkanologie.2015

Ce document a été généré automatiquement le 17 décembre 2020.

(ㄷ) Tous droits réservés 


\section{Varro (Gabrielle), éd., Regards croisés sur l'ex-Yougoslavie. Des chercheurs face à leurs objets de recherche et aux événements sociaux et politiques,}

Paris : L'Harmattan (« Espaces interculturels»), 2005, 246 p.

François Ruegg

\section{RÉFÉRENCE}

Varro (Gabrielle), éd., Regards croisés sur l'ex-Yougoslavie. Des chercheurs face à leurs objets de recherche et aux événements sociaux et politiques, Paris : L'Harmattan (« Espaces interculturels »), 2005, $246 \mathrm{p}$.

1 Ce livre, comme son titre le laisse présager, croise en effet les regards, tant du point de vue des disciplines, de la provenance des auteurs que de l'observation et de la réflexivité. Sociologues, linguistes, politologue, historienne et pédagogue échangent leurs vues et leurs émotions au sujet de cette guerre invraisemblable, tant du point de vue de sa réalité proche que du fait qu'elle a révélé la permanence des instincts et des mécanismes de haine que l'on croyait disparus, au moins dans notre voisinage.

2 Le propos et l'orientation nous sont donnés d'emblée par Gabrielle Varro. Il s'agissait d'abord pour des non spécialistes intéressés à cette crise, réunis par le laboratoire Printemps de l'Université de Versailles Saint-Quentin en 2002, de comprendre et d'analyser leurs réactions face à cet événement: «Ce qui nous réunit enfin et qui constitue la raison d'être de ce volume est donc la tentative d'expliquer notre implication et d'expliciter des positions personnelles » (p. 9). Mais viennent s'y ajouter les vues de chercheurs de l'intérieur, de Bosnie-Herzégovine et de Slovénie, des chercheurs "d'origine yougoslave», ainsi que deux "hors textes" purement historiques. 
3 L'ambition de l'ouvrage est à la fois immense et modeste. Immense dans la mesure il propose d'ajouter à la problématique fort complexe du démembrement de la Yougoslavie les réactions parmi les chercheurs et dans le public. Modeste par ailleurs, puisqu'il n'a pas la prétention d'ajouter de nouvelles hypothèses à celles qu'ont échafaudées les spécialistes. De ce point de vue, ceux qui connaissent un peu l'histoire de la région resteront sur leur faim.

On reconnaîtra certes dans l'orientation de Regards croisés les perspectives postmodernes de l'expression de l'intimité ou des émotions partagées, de la polyphonie anthropologique qui mêle aux voix des observateurs les voix indigènes et celles de la réflexivité enfin : que puis-je apprendre de ces évènements, en quoi modifient-ils ma pratique de recherche. Cependant, ces nouvelles perspectives, redonnant à la subjectivité la place qu'elles croient qu'elle mérite, renouent en fait avec une tradition militante cyclique, celle de l'ethnologie engagée du temps de la décolonisation, celle des philosophes existentialistes, des Romantiques enfin.

5 Les grands thèmes du livre sont l'identité durant et après la guerre, particulièrement en Bosnie-Herzégovine et en Slovénie, qu'elle soit nationale, religieuse, ethnique et linguistique, de genre (J. Heinen) ou composée pour ce qui est des couples mixtes (G. Varro), ou des «Auto-désignations identitaires des originaires d'ex-Yougoslavie » (A. Prohić). Louvoiements entre les termes lourds d'histoire et bien connus, des « Musulmans » aux « Bochniaques » ou « Bosniens » (U. Habul) ou, en ce qui concerne la Slovénie (J. Muršak), nationalisme soft, fait davantage de patriotisme rural régionaliste en raison de l'absence d'État éponyme jusque-là. Pour la langue, P. Sériot montre comment, en Yougoslavie et en ex-Yougoslavie, on a, comme dans d'autres nations auparavant, utilisé la langue pour légitimer tantôt l'unité de destin politique, tantôt la nécessité du divorce. Pour sa part, C. Dubar, dans un article intitulé «Dynamiques identitaires ", qui est aussi une conclusion, reprend la distinction essentia-liste/ nominaliste pour passer en revue les avatars historiques, linguistiques et sociologiques des identités yougoslaves, celles que l'on reçoit et celles que l'on se donne, en s'appuyant sur les grands auteurs classiques, de Durkheim à Weber.

Deux articles me semblent sortir du moule donné par le sous-titre : celui de S. Wahnich «La Yougoslavie hante l'Europe. À propos de quelques manifestations artistiques du spectre » (pp. 55-82) et celui de M. Radenković «La réécriture de l'histoire dans les manuels de Serbie après octobre 2000. Les fonctionnaires de la mémoire » (pp. 137-167). En accomplissant un détour par les arts, la poésie, la photographie et le cinéma, S. Wahnich a le mérite de nous ouvrir d'autres portes, habituellement réservées à des publications plus littéraires, pour comprendre de l'intérieur le drame ou la question yougoslave d'un point de vue "post-historique». "C'est du côté des productions artistiques et culturelles qu'on trouve un foisonnement de dispositifs pour la réfléchir [la matière de l'histoire]»(p. 56). Sur un autre registre, l'analyse détaillée des nouveaux manuels d'histoire en Serbie à laquelle se livre M. Radenković nous fournit, quant à elle, selon une méthode anthropologique plus classique quoique réflexive, des lumières sociologiques intéressantes sur les sources de la nouvelle histoire nationale. Celle-ci oscille en quelque sorte entre deux pôles, l'un nationaliste, en fonction du recrutement provincial de ses membres, l'autre européanisant, issu des " anciennes » élites urbaines. Mais ces deux pensées - «une pensée mythique et une pensée discursive » (p. 167) - charrient toutes deux la mémoire douloureuse d'un passé proche raté, quelle que soit l'explication qu'on en donne, illusion des idées yougoslave et 
socialiste, faute attribuée "aux autres" (du type complot des grandes puissances) ou encore, chances historiques gâchées et malheureux destin. 